\title{
CORRELATION OF WEIGHT-HEIGHT INDEX WITH DIASTOLIC AND WITH SYSTOLIC BLOOD PRESSURE
}

\author{
P. H. SIVE, M.B., Ch.B., M.P.H., D.C.H. \\ AND \\ J. H. MEDALIE, M.B., Ch.B., B.Sc., M.P.H. \\ Department of Family Medicine, Tel Aviv University Medical School \\ H. A. KAHN, M.A. \\ National Heart and Lung Institute, Bethesda, Md., U.S.A. \\ H. N. NEUFELD, M.D. \\ Heart Institute, Tel Hashomer Hospital, and Tel Aviv University Medical School \\ E. RISS, M.D., M.Sc. \\ Heart Institute, Rambam Hospital, Haifa
}

The relationship between blood pressure level and various parameters of body build and obesity has been extensively reported on, and the subject has been recently reviewed by Chiang, Perlman, and Epstein (1969). The relative strength of the correlation of these indices with systolic as compared with diastolic pressure varies. In some studies, the correlation with diastolic pressure was higher than that with systolic pressure (Dawber, Moore, and Mann, 1957; Khosla and Lowe, 1965; Reid, Holland, Humerfelt, and Rose, 1966) and in others, the reverse was reported (Hartman and Ghrist, 1929; Boynton and Todd, 1948; Bøe, Humerfelt, and Wedervang, 1957). These apparently contradictory results may be due in part to the different indices of body build used and, in the report of Hartman and Ghrist, reservations regarding the reliability of the diastolic pressure readings.

In view of these findings it was decided to investigate the correlation of systolic and diastolic pressures with a weight-height index in a population study when each pressure is adjusted for the effect of the other. This paper reports on differences in these correlations obtained from data of the Israel Ischemic Heart Disease Project.

\section{MeTHODS}

The findings relate to blood pressures measured

Address for reprints: Ischemic Heart Disease Project, Tel Hashomer Hospital, Israel. as the last procedure of a physical examination in 1963 of 10,000 Israel male civil service employees aged 40 years and over, carried out in the framework of a large prospective study of ischaemic heart disease (Groen, Medalie, Neufeld, Riss, Bachrach, Mount, and Smith, 1968). (Examinees found to be suffering from hypertension or ischaemic heart disease were not excluded from analysis.) The blood pressure was measured according to the method recommended by the World Health Organization (1959) using a standard mercury sphygmomanometer, a $22 \times 12 \mathrm{~cm}$. bladder and Velcro fastener, the examinee being recumbent. The systolic pressure was measured at eye level at the onset of the sounds and the diastolic pressure at the point of disappearance of the Korotkow sounds, or of their muffling in cases in which they did not disappear. The standardization of all phases of blood pressure measurement was carefully supervised following training sessions in methods for the physicians. Analysis of frequency distributions of all blood pressures recorded by individual physicians showed one who tended to measure higher pressures than his colleagues. The number of subjects he examined, however, was too small $(2.4 \%$ of the total) to have any effect on the final results.

The measurement of body build used in the present study is the weight-height index, $\frac{\text { Weight in } \mathrm{kg} \text {. }}{\text { Height in } \mathrm{cm} \text {. }} \mathrm{K}, \mathrm{K}$ being such that $\frac{\mathrm{kg} .}{\mathrm{cm} \text {. }} \mathrm{K}=\frac{\mathrm{lb} \text {. }}{\mathrm{in} \text {. }}$ 
After consideration of the various relative weight ratios and weight-height indices which are practicable in a large-scale epidemiological survey and in the absence of a clear consensus as to which of these is in fact most useful for our purposes, it was decided to choose the simplest.

In keeping with the finding of Khosla and Lowe (1965) the correlation of blood pressure with arm circumference was found to disappear when adjustment was made for the weight-height index.

\section{Findings}

Simple correlation coefficients between the weight-height index and blood pressure were greater for diastolic than for systolic pressure in each of the six areas of birth used to sub-divide our total study population (Table I). This observation,

TABLE I

SIMPLE CORRELATION COEFFICIENT OF BLOOD PRESSURE WITH WEIGHT-HEIGHT INDEX BY AREA OF BIRTH

\begin{tabular}{|c|c|c|c|}
\hline Area of Birth & No. of Cases & $\begin{array}{r}\text { Bloo } \\
\text { Systolic }\end{array}$ & $\begin{array}{l}\text { ure } \\
\text { Diastolic }\end{array}$ \\
\hline $\begin{array}{l}\text { Israel } \\
\text { Eastern Europe } \\
\text { Central Europe } \\
\text { Southern Europe } \\
\text { Middle East } \\
\text { (excl. Israel) } \\
\text { North Africa }\end{array}$ & $\begin{array}{l}1,430 \\
1,918 \\
1,371 \\
1,731 \\
2,367 \\
1,217\end{array}$ & $\begin{array}{l}0 \cdot 14 \\
0 \cdot 14 \\
0 \cdot 18 \\
0 \cdot 17 \\
0 \cdot 18 \\
0 \cdot 25\end{array}$ & $\begin{array}{l}0 \cdot 21 \\
0 \cdot 18 \\
0 \cdot 22 \\
0 \cdot 23 \\
0 \cdot 30 \\
0 \cdot 32\end{array}$ \\
\hline Total & 10,034 & $0 \cdot 17$ & 0.25 \\
\hline
\end{tabular}

together with the fact that the correlation between systolic and diastolic blood pressure is about 0.75 in each area, led to the thought that a large part of the systolic correlation with obesity may simply be a reflection of diastolic correlation. Accordingly, we computed the partial correlation coefficients between systolic blood pressure and the weight-height index after adjustment for diastolic pressure and also those between diastolic pressure and weight-height index after adjustment for systolic pressure. These coefficients can be under- stood by considering that a partial coefficient between $X_{1}$ and $X_{2}$ with adjustment for $X_{8}$ is the average of the various coefficients $r_{12}$ that could be computed at fixed levels of $X_{3}$.

The partial correlation coefficients of weightheight index with one of the blood pressure measurements after adjustment for the other blood pressure measurement are shown in Table II. In

TABLE III

CORRELATION COEFFICIENTS BETWEEN DIASTOLIC PRESSURE AND WEIGHT-HEIGHT INDEX ADJUSTED FOR SYSTOLIC PRESSURE BY AGE

\begin{tabular}{c|c|c}
\hline \multicolumn{1}{c|}{ Age (years) } & No. of Cases & \\
\hline $40-44$ & 3,307 & \\
\hline $45-49$ & 2,104 & $0 \cdot 16$ \\
$50-54$ & 2,176 & $0 \cdot 21$ \\
$55-59$ & 1,486 & $0 \cdot 20$ \\
$60+$ & 961 & $0 \cdot 13$ \\
Total & 10,034 & $0 \cdot 17$ \\
\hline
\end{tabular}

each of the six areas, the 0.95 confidence limits (this is the range estimated to include the true coefficient in $95 \%$ of all samples, using the methods we have used) for the partial correlation of systolice pressure with weight-height index after adjusting 8 for diastolic pressure either include zero or are entirely in the negative range. The 0.95 confidence limits for the partial correlation coefficients of? diastolic pressure with weight-height index after adjusting for systolic pressure do not extend below +0.08 in any of the six areas.

A further finding was that the correlation between diastolic pressure and weight-height index adjusted for systolic pressure showed no trend with age (Table III).

\section{Discussion}

It is concluded from the findings that the correlation of systolic blood pressure with weight-height index appears to be an indirect finding dependent upon the correlation between this index of relative

TABle II

PARTIAL CORRELATION COEFFICIENTS WITH WEIGHT-HEIGHT INDEX BY AREA OF BIRTH

\begin{tabular}{|c|c|c|c|c|}
\hline Area of Birth & Systolic & (adjusted for diastolic) & Diastolic & (adjusted for systolic) \\
\hline $\begin{array}{l}\text { Israel } \\
\text { Eastern Europe } \\
\text { Central Europe } \\
\text { Southern Europe } \\
\text { Middle East (excl. Israel) } \\
\text { North Africa }\end{array}$ & $\begin{array}{r}-0.02 \\
-0.00 \\
0.00 \\
-0.00 \\
-0.06 \\
0.02\end{array}$ & $\begin{array}{l}(-0.07 \text { to } 0.03) \\
(-0.05 \text { to } 0.04) \\
-0.05 \text { to } 0.06) \\
-0.05 \text { to } 0.04) \\
(-0.10 \text { to }-0.02) \\
(-0.03 \text { to } 0.08)\end{array}$ & $\begin{array}{l}0 \cdot 16 \\
0 \cdot 12 \\
0 \cdot 14 \\
0 \cdot 16 \\
0 \cdot 25 \\
0 \cdot 22\end{array}$ & $\begin{array}{l}(0.10 \text { to } 0.20) \\
(0.08 \text { to } 0.17) \\
(0.09 \text { to } 0.19) \\
(0.11 \text { to } 0.20) \\
(0.21 \text { to } 0.29) \\
(0.17 \text { to } 0.27)\end{array}$ \\
\hline Total & -0.02 & $(-0.04$ to 0.00$)$ & $0 \cdot 18$ & $(0.17$ to 0.20$)$ \\
\hline
\end{tabular}

0.95 confidence limits in parentheses 
weight and diastolic blood pressure and the high correlation between systolic and diastolic pressure. The observed association with diastolic pressure may be the result of a blood pressure measurement bias associated with body size which affects diastolic but not systolic pressures. We know of no evidence pointing in this direction and tentatively assume the association between weight-height index and diastolic pressure to be a true one. An explanation for this basic association of diastolic pressure with weight-height index must be sought in physiological terms.

Since peripheral resistance is the prevailing determinant of the level of diastolic pressure, this is the factor which would seem worthy of further study in relation to the association of a weightheight index with blood pressure. Interest is thus focused on the structural and functional circulatory changes resulting from increased body bulk, due most often to obesity. The association of obesity with increased blood pressure may result from the effects of atherosclerosis either on the vascular walls or indirectly via the renal mechanisms of hypertension. The present findings give no support to the importance of these factors since the correlation coefficients between diastolic blood pressure and weight-height index were not greater with increase in age as would be expected with a progressive process such as atherosclerosis. Moreover, the males aged 40 and over in the study population show no evidence of increase in weight with rising age (Medalie, Kahn, Neufeld, Riss, and Groen, 1968), suggesting that any effect on blood pressure level due to increase in weight has already occurred by age 40 .

It is well recognized clinically that many very obese patients have normal blood pressures. Whyte (1959) has concluded that it is not the fat content but overall body bulk that accounts for the correlation between body size and blood pressure. In their review of the subject, Grande and Taylor (1965) conclude that there is no support for the view that obesity is involved in the causation of hypertension. They point out that in the case of extreme obesity with normal blood pressure and elevated cardiac output, the computed vascular resistance is decreased.

Brod, Fencl, Hejl, and Jirka (1959) and Brod, Fencl, Hejl, Jirka, and Ulrych (1962) have described alterations in peripheral resistance in various sites in different types of hypertension, e.g., lack of decreased vascular resistance in muscle in essential and acute stress-induced hypertension as compared with normal muscle blood flow in renal hypertension. The question arises whether different types of causes of obesity have different effects on cardiovascular dynamics which do not always result in the raised blood pressure generally associated with overweight. As originally proposed by Tibblin (1967), both obesity and raised blood pressure may be the commonly associated effects of a third underlying factor. It is suggested that different types of body constitution are associated with hormone and electrolyte mechanisms which are responsible for a range of effects on diastolic blood pressure level and body size which frequently, but not always, result in the concomitant increase of both these parameters. Long-term prospective studies on younger populations would be required to examine such a contention.

\section{SUMMARY}

The significant correlation found between diastolic blood pressure and a weight-height index in the 10,000 male population aged 40 and over of the Israel Ischemic Heart Disease Project remained when adjustment was made for systolic pressure. However, the correlation of systolic pressure with weight-height index disappeared when adjustment was made for diastolic pressure. No trend with age was noted for the correlation between diastolic pressure and weight-height index. It is concluded that the frequently reported correlation between systolic pressure and overweight is simply a reflection of the more basic association of diastolic pressure with overweight.

It is suggested that this correlation may be the result of hormone and electrolyte effects characterizing different types of body constitution.

This study was supported by PL 480 Counterpart Funds, Research Agreement No. 375106 in a collaborative project of the National Heart Institute Bethesda, Md., U.S.A., the Ministry of Health and Hadassah Medical Organization, Jerusalem, Israel.

\section{REFERENCES}

Bge, J., Humerfelt, S., and Wedervang, F. (1957). The blood pressure in a population. Acta med. scand., Suppl. 321.

Boynton, R. E., and TodD, R. L. (1948). Relation of body weight and family history of hypertensive disease to blood pressure levels in university students. Amer. J. med. Sci., 216, 397.

Brod, J., Fencl, V., Hejl, Z., and Jirka, J. (1959). Circulatory changes underlying blood pressure elevation during acute emotional stress (mental arithmetic) in normotensive and hypertensive subjects. Clin. Sci., 18, 269.

,,,---- , and UlRYCH, M. (1962). General and regional haemodynamic pattern underlying essential hypertension. Clin. Sci., 23, 339. 
Chilang, B. N., Perlman, L. V., and Epstenn, F. H. (1969). Overweight and hypertension: a review. Circulation, 39, 403.

DAWber, T. R., Moore, F. E., and MaNn, G. V. (1957). Coronary heart disease in the Framingham study. Amer. J. publ. Hlth, 47, no. 4, Part 2 (Suppl.), p. 4.

GraNDE, F., and TAYLOR, H. L. (1965). Adaptive changes in the heart, vessels, and patterns of control under chronically high loads. In Handbook of Physiology. Section 2: Circulation, Vol. 3, p. 2641. American Physiological Society, Washington, D.C.

Groen, J. J., Medalie, J. H., Neufeld, H. N., Riss, E., Bachrach, C. A., Mount, F. W., and Smith, H. (1968). An epidemiologic investigation of hypertension and ischemic heart disease within a defined segment of the adult male population of Israel. Israel J. med. Sci., 4, 177.

Hartman, H. R., and Ghrist, D. G. (1929). Blood pressure and weight. Arch. intern. Med., 44, 877.
Krosla, T., and Lowe, C. R. (1965). Auterial pressure and arm circumference. Brit. J. prev. soc. Med., 19, 159.

Medalie, J. H., KaHN, H. A., Neufeld, H. N., Riss, E., and Groen, J. J. (1968). Physician's Fact Book. Selected Measurements on 10,000 Israeli Males, p. 3. Israel Ischemic Heart Disease Study, Jerusalem

Reid, D. D., Holland, W. W., Humerfelt, S., and Rose, G. (1966). A cardiovascular survey of postal workers. Lancet, 1, 614.

TibBlin, G. (1967). High blood pressure in men aged 50. Acta med. scand., Suppl. 470.

World Health Organization (1959). Hypertension and coronary heart disease: classification and criteria for epidemiological studies. Techn. Rep. Ser., No. 168.

Whyte, H. M. (1959). Blood pressure and obesity. Circulation, 19, 511. 